\title{
Intercomparison and Interpretation of Single-Column Model Simulations of a Nocturnal Stratocumulus-Topped Marine Boundary Layer
}

\author{
Ping Zhu,* Christopher S. Bretherton, ${ }^{*}$ Martin Köhler, ${ }^{+}$Anning Cheng, \# Andreas Chlond, \\ Quanzhen Geng, \& Phil Austin, \& Jean-Christophe Golaz,** Geert Lenderink, ${ }^{+}+$ \\ Adrian Lock, \#\# AND BJORn STEVEns $@$ \\ *Department of Atmospheric Sciences, University of Washington, Seattle, Washington \\ +European Centre for Medium-Range Weather Forecasts, Reading, United Kingdom \\ \#NASA Langley Research Center, Hampton, Virginia \\ @ Max Planck Institute for Meteorology, Hamburg, Germany \\ \&University of British Columbia, Vancouver, British Columbia, Canada \\ **National Research Council, Naval Research Laboratory, Monterey, California \\ ++ Koninklijk Nederlands Meteorologisch Institute, De Bilt, Netherlands \\ \#\#United Kingdom Meteorological Office, Exeter, Devon, United Kingdom \\ @@Department of Atmospheric and Oceanic Sciences, University of California, Los Angeles, Los Angeles, California
}

(Manuscript received 15 September 2004, in final form 31 January 2005)

\begin{abstract}
Ten single-column models (SCMs) from eight groups are used to simulate a nocturnal nonprecipitating marine stratocumulus-topped mixed layer as part of an intercomparison organized by the Global Energy and Water Cycle Experiment Cloud System Study, Working Group 1. The case is idealized from observations from the Dynamics and Chemistry of Marine Stratocumulus II, Research Flight 1. SCM simulations with operational resolution are supplemented by high-resolution simulations and compared with observations and large-eddy simulations. All participating SCMs are able to maintain a sharp inversion and a mixed cloud-topped layer, although the moisture profiles show a slight gradient in the mixed layer and produce entrainment rates broadly consistent with observations, but the liquid water paths vary by a factor of 10 after only $1 \mathrm{~h}$ of simulation at both high and operational resolution. Sensitivity tests show insensitivity to activation of precipitation and shallow convection schemes in most models, as one would observationally expect for this case.
\end{abstract}

\section{Introduction}

Marine stratus and stratocumulus cloud (MSC), which usually forms from 500 to $1000 \mathrm{~m}$ above the ocean surface and is a few hundred meters in thickness, plays a crucial role in the global climate system by enhancing the global albedo and promoting turbulent heat and moisture exchange between the sea surface, the boundary layer, and the overlying troposphere. Despite improvements in observing, understanding, and modeling of MSC, serious biases persist in its horizontal extent, vertical structure, and mean albedo simulated by most general circulation models (GCMs; Gordon et

Corresponding author address: Dr. Ping Zhu, Department of Atmospheric Sciences, University of Washington, Seattle, WA 98195.

E-mail:pzhu@cgd.ucar.edu al. 2000). Likely causes include inaccurate parameterizations of turbulence and entrainment, cloud fraction, cloud microphysics, and precipitation, as well as insufficient vertical resolution.

As a part of the Global Energy and Water Cycle Experiment (GEWEX) Cloud System Study (GCSS; Browning 1993), Working Group 1 (WG1) has organized a series of large-eddy simulation (LES) and single-column model (SCM) intercomparison studies of stratocumulus- and cumulus-cloud-topped boundary layers. The methodology of GCSS WG1 is to (i) use LES to simulate turbulence-cloud-radiation interactions and deduce mean cloud fraction, thickness, and vertical structure in a variety of climatologically important cloud regimes; (ii) test and improve SCMs using the LES results; and (iii) test the fidelity of both LES and SCM results using intercomparisons based on wellobserved case studies. 


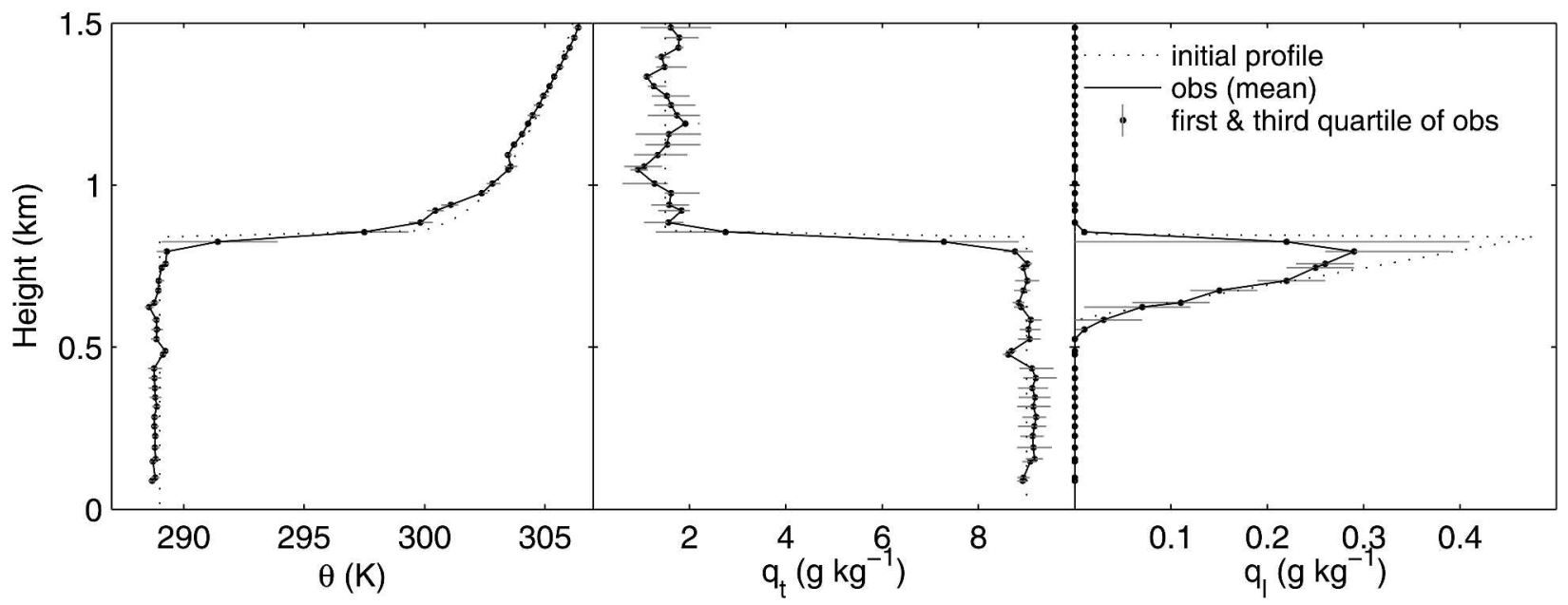

FIG. 1. Observed vertical thermodynamic profiles from RF01 along with profiles used for model initialization (superposed dotted line). Dark lines with dots are the average values over all profiles during the flight. Light horizontal lines indicate the first and third quartiles of the observed values.

The first WG1 intercomparison (Moeng et al. 1996; Bechtold et al. 1996) immediately showed the value of this methodology but also some pitfalls in achieving it. This intercomparison focused on an idealized nocturnal nonprecipitating stratocumulus-topped boundary layer (STBL), driven mainly by cloud-top longwave radiative cooling. The goal was to compare the turbulent structure and particularly the entrainment of free atmosphere into the boundary layer, as these processes control the evolution of cloud thickness, fraction, and albedo. By avoiding solar absorption by clouds and possible drizzle processes, the intercomparison was simple and easy to interpret and attracted a broad group of LES and SCM modelers. However, only very limited validation data were available for this idealized case, especially regarding the entrainment rate. One alarming finding of this intercomparison was that there was a sixfold variation in the simulated entrainment rate among the participating LES models and a fourfold variation in SCM-predicted entrainment rate. In most LES and SCM models, the simulated liquid water path (LWP) decreased two- to threefold in the first hour to unrealistically small values, suggesting excessive dry air entrainment. While the scatter in entrainment was partly due to the ambiguities in the case specification of downwelling longwave radiation, the subsequent WG1 study of an even more idealized and tightly controlled radiatively driven "smoke cloud" boundary layer (Bretherton et al. 1999) confirmed that the entrainment rates were overestimated by up to twofold by LESs and threefold by SCMs compared with a laboratory analog. Very high vertical resolution (5-10 m) LESs overestimated entrainment rates less severely.
Recently, Duynkerke et al. (2004) presented an LES and SCM intercomparison study of the diurnal cycle of marine stratocumulus by the European Project on Cloud Systems (EUROCS). This case was loosely based on observations at San Nicolas Island off the California coast. Both the mean and diurnal variation of subsidence rate and initial profiles were chosen in practice to optimize LES-observation agreement. Although the model-predicted entrainment rates show less spread than previous studies, LWP varied greatly (more than 10-fold) among participating SCMs. The diurnal cycle of solar absorption rendered this case more complex and difficult than the nocturnal STBL.

The Dynamics and Chemistry of Marine Stratocumulus (DYCOMS-II) experiment (Stevens et al. 2003a) was specifically designed to accurately measure the entrainment rates associated with nocturnal marine stratocumulus. It took place during July 2001 in the northeast Pacific stratocumulus regime, approximately 500 $\mathrm{km}$ west-southwest of San Diego, California. Research Flight 1 (RF01), documented by Stevens et al. (2003b), provides a particularly attractive intercomparison case for realizing the vision of GCSS. Figure 1 shows the observed thermodynamic structure of this case, a wellmixed boundary layer capped by a quite horizontally homogeneous cloud layer with negligible drizzle below cloud base. Estimates of entrainment rates based on different observations and methods were fairly consistent, yielding a consensus value of $0.4 \pm 0.08 \mathrm{~cm} \mathrm{~s}^{-1}$, which is probably the most reliable in situ estimate ever made for a subtropical STBL. Stevens et al. (2003b) also presented an LES simulation in encouraging agreement with the observations. Another intriguing feature 
TABLE 1. Participating SCMs and their features.

\begin{tabular}{|c|c|c|c|c|}
\hline Model & Investigator & Stratiform cloud scheme & PBL turbulence scheme & $\begin{array}{c}\text { Levels }<1200 \mathrm{~m} / \text { total } \\
\Delta z \text { near } 840 \mathrm{~m}\end{array}$ \\
\hline CCCma-UBC & Geng-Austin & $\begin{array}{l}\text { Prognostic cloud water } \\
\text { Diagnostic cloud fraction }\end{array}$ & Bulk nonlocal $K$-profile & $9 / 35131 \mathrm{~m}$ \\
\hline METO & Lock & Diagnostic cloud & $\begin{array}{l}\text { First order, nonlocal } \\
\text { Explicit cloud-top entrainment }\end{array}$ & $9 / 15175 \mathrm{~m}$ \\
\hline RPN & Lock & Diagnostic cloud & TKE closure & $9 / 15175 \mathrm{~m}$ \\
\hline KNMI & Lenderink & $\begin{array}{l}\text { Prognostic cloud water } \\
\text { Diagnostic cloud fraction }\end{array}$ & TKE closure & $19 / 2488 \mathrm{~m}$ \\
\hline NCAR-CAM & Zhu-Bretherton & $\begin{array}{l}\text { Prognostic cloud water } \\
\text { Diagnostic cloud fraction }\end{array}$ & Bulk nonlocal & $6 / 30117 \mathrm{~m}$ \\
\hline CAM-UW & Zhu-Bretherton & $\begin{array}{l}\text { Prognostic cloud water } \\
\text { Diagnostic cloud fraction }\end{array}$ & $\begin{array}{l}\text { TKE closure } \\
\text { Explicit cloud-top entrainment }\end{array}$ & $6 / 30117 \mathrm{~m}$ \\
\hline NRL & Golaz & $\begin{array}{l}\text { Diagnostic cloud water } \\
\text { Diagnostic cloud fraction }\end{array}$ & Partial third-order closure & N/A \\
\hline NASA-LaRC & Cheng & $\begin{array}{l}\text { Prognostic cloud water } \\
\text { Diagnostic cloud fraction }\end{array}$ & Partial third-order closure & $12 / 15100 \mathrm{~m}$ \\
\hline MPI & Chlond & $\begin{array}{l}\text { Prognostic cloud water } \\
\text { Diagnostic cloud fraction }\end{array}$ & $\begin{array}{l}\text { TKE closure } \\
\text { Explicit cloud-top entrainment }\end{array}$ & $12 / 15120 \mathrm{~m}$ \\
\hline ECMWF & Köhler & $\begin{array}{l}\text { Quasi-prognostic total water } \\
\text { Variance moist thermodynamics }\end{array}$ & $\begin{array}{l}\text { Eddy diffusivity/mass flux } \\
\text { Explicit cloud-top entrainment }\end{array}$ & $12 / 60201 \mathrm{~m}$ \\
\hline
\end{tabular}

of this case was that the inversion jumps satisfied the buoyancy reversal criterion for cloud-top entrainment instability (CTEI; Randall 1980; Deardorff 1980). If present, CTEI would lead to a desiccation of the marine layer. Yet, the observed cloud was quite steady (slightly thickening) throughout RF01. Stevens et al. (2003b) argued that other processes may be simply strong enough in this case to dominate the tendency of buoyancy reversal processes to thin the cloud, since CTEI is a complicated process that is closely related to boundary layer turbulent circulations and the details of entrainment, rather than just the thermodynamic conditions across the interface. Hence, GCSS WG1 selected this case to revisit whether LES and SCM simulations of nocturnal nonprecipitating stratocumulus are now more consistent than nine years ago after steady refinements in parameterization of boundary layer processes, such as more precise treatments of cloud-top entrainment and moist turbulent processes.

This paper reports the results of the SCM part of this intercomparison study, which includes 10 SCM runs by eight participating groups. The key issues addressed here are as follows:

- How do SCM simulations compare to LESs when run at comparably high vertical resolution?

- To what extent can SCMs with operational resolution reproduce the observed STBL structure, entrainment rate, and LWP under the specified conditions and forcings?

- Do SCMs reproduce the observed lack of drizzle? Do parameterized precipitation and shallow convection affect the simulations?

- What insights are gained from comparing SCM simulations with the participating LESs?

Stevens et al. (2005, hereafter STE) present the accompanying LES intercomparison for this case.

\section{Simulation strategy}

\section{a. Participating models}

Table 1 briefly documents the 10 participating SCMs, including their stratiform cloud and boundary layer turbulence parameterizations and three measures of their operational vertical resolution: the number of model levels below $1200 \mathrm{~m}$ and in total, and the grid spacing $\Delta z$ at the base of the inversion $z_{i}=840 \mathrm{~m}$. The Naval Research Laboratory (NRL) SCM did not execute the simulations with operational resolution; thus no such information was provided. Only the European Centre for Medium-Range Weather Forecasts (ECMWF), National Center for Atmospheric Research Community Atmospheric Model (NCAR-CAM), Community Atmospheric Model with University of Washington PBL scheme (CAM-UW), and Canadian Centre for Climate Modelling and Analysis-University of British Columbia (CCCma-UBC) SCMs use a grid suitable for GCM simulation; the others have been especially configured for this particular simulation, with few levels above $1200 \mathrm{~m}$. The ECMWF SCM uses several new physical 
parameterizations targeted for future introduction into their operational forecast model, including a new boundary layer parameterization and a new approach for predicting cloud fraction and condensate.

Six of the 10 SCMs [CCCma-UBC, Koninklijk Nederlands Meteorologisch Institute (KNMI), National Aeronautics and Space Administration Langley Research Center (NASA-LaRC), NCAR-CAM, CAMUW, and Max Planck Institute (MPI)] determine cloud condensate prognostically, while the other four calculate cloud condensate diagnostically. All models diagnose subgrid cloud cover fraction based on either relative humidity (e.g., CCCma-UBC, NCAR-CAM) or probability density function (PDF) of conserved variables such as $\theta_{l}$ and $q_{t}$ [e.g., Recherche en Prévision Numérique (RPN), NRL, and NASA-LaRC]. The ECMWF SCM prognoses the grid-mean and subgrid variance of total water specific humidity, from which cloud fraction and cloud water are diagnosed (Tompkins 2002).

The boundary layer turbulence schemes used by the SCMs are quite diverse. They can be classified according to (i) their formulation of mixing within the STBL, (ii) whether they account for ("moist") or neglect ("dry") moist thermodynamics in calculating stratification of partially or totally saturated layers, and (iii) whether cloud-top entrainment is explicitly computed or an implicit consequence of the model's mixing scheme.

The U.K. Meteorological Office (METO), CCCmaUBC, and NCAR-CAM SCMs use bulk nonlocal $K$ profile schemes. The NCAR-CAM and CCCma-UBC scheme is dry and surface-driven, while the METO scheme is moist and accounts for turbulence production by cloud-top radiative and evaporative cooling (Lock et al. 2000). The remaining SCMs use turbulence closure models of various complexity levels. The RPN, KNMI, CAM-UW, and MPI SCMs determine turbulent diffusivity based on prognostic turbulent kinetic energy (TKE). The NRL (Golaz et al. 2002; Larson and Golaz 2005) and NASA-LaRC (Cheng et al. 2004) SCMs are both partially prognostic third-order closure schemes. They predict second-order moments of $w, \theta_{l}, q_{t}$, and a limited number of third-order moments. NRL predicts only one third-order moment $\left(\overline{w^{\prime 3}}\right)$, while NASALaRC predicts three third-order moments $\overline{\left(w^{\prime 3}\right.}, \overline{\theta_{l}^{\prime 3}}$, and $\left.\overline{q_{t}^{\prime 3}}\right)$. Both schemes diagnose the other high-order moments based on a PDF determined from the predicted moments. The new ECMWF model uses an eddydiffusivity/mass-flux approach, which combines a $K$ profile diffusion term with a mass-flux term to describe nonlocal transports (Tompkins et al. 2004).

Four SCMs (METO, ECMWF, CAM-UW, and MPI) employ an explicit entrainment parameterization at the top of buoyancy-driven boundary layers. In the METO, ECMWF, and CAM-UW SCMs, the entrainment parameterization includes both evaporative and radiative cooling effects when the boundary layer is topped by clouds. In the METO and ECMWF models, the entrainment rate $W_{e}$ is explicitly computed following Lock et al. (2000) as

$$
W_{e}=A_{1} \frac{V^{3}}{\Delta B}+A_{2} \frac{\Delta F}{\Delta B},
$$

where $V$ is a diagnosed turbulence velocity scale, $\Delta B$ is the buoyancy jump across the inversion, $\Delta F$ is the cloud-top radiative flux divergence, and $A_{1}$ and $A_{2}$ are empirical coefficients. The CAM-UW model incorporates $\Delta F$ into the calculation of $V$, and takes $A_{2}=0$. The MPI entrainment parameterization only considers cloud-top radiative cooling $\left(A_{1}=0\right)$. Cloud-top entrainment is not explicitly represented in the KNMI SCM but it is implicitly included in the moist turbulence scheme by adjusting the turbulent mixing length (1) via

$$
\frac{1}{l}=\frac{1}{l_{0}}+\frac{1}{C_{e} \sqrt{\mathrm{TKE} / N}},
$$

where $N$ is Brunt-Väisälä frequency, and the constant $C_{e}$ is chosen to obtain reasonable entrainment rates through strong inversions (Lenderink and Holtslag 2000).

Models also differ in their operational vertical resolution and the organization of the physical parameterizations. Such a diversity, in a way, makes attribution of differences between model results harder to interpret, but on the other hand, it provides a great opportunity to look at the behavior of a similar type of parameterization in a different model framework. In addition to that, intercomparison also allows a close examination of different schemes in the same model framework; for example, the NCAR-CAM and CAM-UW simulations are particularly illuminating to compare since they only differ in their boundary layer and shallow convection schemes. A detailed comparison of SCM and global simulations between NCAR-CAM and CAM-UW will be presented in forthcoming papers by P. Zhu and C. S. Bretherton (2005, unpublished manuscript, hereafter ZB) and C. S. Bretherton and P. Zhu (2005, unpublished manuscript, hereafter BZ).

The companion LES intercomparison consists of 10 LES models differing mainly in their numerical algorithms and the treatment of subscale motions. A total of sixteen 4-h simulations were executed under the same initial conditions and external forcings on a grid 
mesh of 96 by 96 points in horizontal with a grid spacing of $35 \mathrm{~m}$ and a vertical grid spacing of $5 \mathrm{~m}$ or less in the vicinity of cloud top. Statistical analyses were then applied to individual runs to obtain a simulation ensemble. Detailed descriptions of models and analysis methods are provided by STE.

\section{b. Numerical setup}

To run an SCM, one needs to specify initial conditions, such as dynamic and thermodynamic vertical profiles, and external forcings, such as horizontal and vertical advections. The initial conditions and external forcings of the DYCOMS-II case for SCM simulations are specified based on the observations during RF01 and are the same as those for the companion LES intercomparison. Because of the nature of LES, which integrates from a nonturbulent state to a fully turbulent state, these conditions and forcings have been idealized in such a way that the important observed features of STBL can be best represented by LESs after reaching quasi steady state. STE provides more rationale for the exact case specifications, but these are also included here for reference.

Based on observations, the initial thermodynamic profiles are

$$
\begin{aligned}
& \theta_{l}=\left\{\begin{array}{cc}
289 \mathrm{~K}, & \text { if } z<z_{i} \\
297.5+\left(z-z_{i}\right)^{1 / 3} \mathrm{~K}, & \text { otherwise }
\end{array}\right. \\
& q_{t}= \begin{cases}9.0 \mathrm{~g} \mathrm{~kg}^{-1}, & \text { if } z<z_{i} \\
1.5 \mathrm{~g} \mathrm{~kg}^{-1}, & \text { otherwise }\end{cases}
\end{aligned}
$$

where $\theta_{l}$ is the liquid water potential temperature; $q_{t}$, the total specific humidity; $z$, the height above the surface; and $z_{i}=840 \mathrm{~m}$ the base of the inversion, equivalent to the top of the cloud layer. These profiles compare well with the observed vertical thermodynamic structure shown in Fig. 1, which remained nearly constant throughout RF01 (Stevens et al. 2003b).

To obtain the observed boundary layer mean winds $\left(U=6 \mathrm{~m} \mathrm{~s}^{-1}, V=-4.25 \mathrm{~m} \mathrm{~s}^{-1}\right)$, vertically uniform geostrophic winds are specified to be $U_{g}=7 \mathrm{~m} \mathrm{~s}^{-1}$ and $V_{g}=-5.5 \mathrm{~m} \mathrm{~s}^{-1}$, as are the initial winds. The surface pressure is taken as $1017.8 \mathrm{hPa}$.

Since observations showed a fairly uniform largescale environment with a weak horizontal advection, the horizontal advective tendency of temperature and moisture are set to zero. The large-scale horizontal wind divergence is set to be $D=3.75 \times 10^{-6} \mathrm{~s}^{-1}$, which gives a large-scale subsidence rate of about -0.32 $\mathrm{cm} \mathrm{s}^{-1}$ at the cloud top. This subsidence rate was chosen to reconcile the thermal structure above the boundary layer with the deduced radiative fluxes and was in a
TABLE 2. Characteristics of the numerical experiments. SHF: sensible heat flux; LHF: latent heat flux.

\begin{tabular}{cccc}
\hline \hline Experiment & Integration & Surface condition & $\begin{array}{c}\text { Time step } \\
\text { resolution }\end{array}$ \\
\hline A & $6 \mathrm{~h}$ & $\mathrm{SHF}=15 \mathrm{~W} \mathrm{~m}^{-2}$ & $5 \mathrm{~s}$ \\
& & $\mathrm{LHF}=115 \mathrm{~W} \mathrm{~m}^{-2}$ & $10 \mathrm{~m}$ \\
$\mathrm{~B}$ & $48 \mathrm{~h}$ & $\mathrm{SST}=292.5 \mathrm{~K}$ & $\begin{array}{c}1800 \mathrm{~s} \\
\text { Operational }\end{array}$ \\
\end{tabular}

good agreement with operational analyses for the study location and time period.

To minimize the different impact of radiative forcing arising from various radiative schemes, all participating SCMs and LESs used the following idealized formulation for calculating the net longwave radiative flux:

$$
\begin{aligned}
F(z)= & F_{0} e^{-Q(z, \infty)}+F_{1} e^{-Q(0, z)} \\
& +\rho C_{p} D\left[\frac{\left(z-z_{i}\right)^{4 / 3}}{4}+z_{i}\left(z-z_{i}\right)^{1 / 3}\right],
\end{aligned}
$$

where

$$
Q(a, b)=\kappa \int_{a}^{b} \rho q_{l} d z,
$$

$q_{l}$ is liquid water specific humidity, and $\rho$ and $C_{p}$ denote air density and isobaric specific heat of air. Following the specification of the LES intercomparison, the SCM boundary layer top $z_{i}$ is defined at the height where $q_{t}=8 \mathrm{~g} \mathrm{~kg}^{-1}$. The three terms on the left-hand side of Eq. (3) represent cloud-top radiative cooling, cloudbase radiative warming, and inversion-layer cooling effect, respectively. The parameters $\kappa, F_{0}$, and $F_{1}$ are chosen as $85 \mathrm{~m}^{2} \mathrm{~kg}^{-1}, 70 \mathrm{~W} \mathrm{~m}^{-2}$, and $22 \mathrm{~W} \mathrm{~m}^{-2}$, respectively, to match radiative fluxes from a $\delta$-four stream radiative code.

Table 2 summarizes the two principal types of simulation used for the SCM intercomparison. For both, all models were run with their shallow cumulus parameterization active. This is because turbulence schemes in several SCMs, such as RPN and NRL, include cumulus convection as a form of turbulence, so that it is not possible to switch off shallow convection in these models. The only exception was KNMI, which was run without its shallow convection scheme for all simulations.

Precipitation and deep convection schemes were switched off in models during the simulations. Again, there was one exception. In the ECMWF simulations, the deep convection scheme was turned on, but it was not triggered during these simulations; therefore, it basically does not have an effect on simulations. Both 
experiments A and B were nocturnal (no insolation). Experiment A was designed to compare the SCM simulations at high vertical resolution with LES results; thus, it closely follows the LES case specification of a 6-h simulation with a high vertical resolution of $10 \mathrm{~m}$ (and a time step of $5 \mathrm{~s}$, unless otherwise noted), forced by a fixed surface sensible heat flux of $15 \mathrm{~W} \mathrm{~m}^{-2}$ and a latent heat flux of $115 \mathrm{~W} \mathrm{~m}^{-2}$. Experiment $\mathrm{B}$ was designed to test SCMs at their operational vertical resolution using a 48-h simulation. To reduce model drift, a fixed SST of $292.5 \mathrm{~K}$ is specified, so that the surface heat fluxes are determined interactively in experiment $B$ rather than in experiment $A$.

The results of experiment B are also compared with an identically forced 48-h simulation using the University of California, Los Angeles (UCLA) LES. This LES is further described by STE. For the 48-h simulation, it was run with no subgrid-scale turbulence scheme applied to scalars and with a vertical grid spacing of $5 \mathrm{~m}$ between 775 and $1025 \mathrm{~m}$, stretching to $10 \mathrm{~m}$ below this layer and continually stretched above, that is, the UCLA-0 configuration as described in STE. An experiment-A simulation with this configuration was quite consistent with observations (STE). Unfortunately, the inversion rose through the top of the refined grid around hour 40, leading to a spurious increase in entrainment and decrease in liquid water path and cloud cover in the next few hours. Hence, we will show UCLA-LES results only up through hour 36 .

The sensitivity of the simulations to modeled precipitation processes and shallow convection was also explored by a number of groups.

Because of the limitation of model design, not every model can be configured to a specified high vertical resolution or to the requested sensitivity tests. Table 3 summarizes the numerical experiments executed by various SCMs. The NRL model was targeted for regional weather prediction and was not designed to run with an 1800-s time step. Therefore, it was only used for experiment A.

\section{Simulation results}

\section{a. Experiment $A$}

The time variation of the simulated total cloud cover fraction and vertically integrated LWP from experiment A are shown in Fig. 2, along with LES-predicted values and their standard deviations. STE lumped the LES simulations into LWP quartiles, and found that the highest-LWP quartile matched the observations much better than the other quartiles. Our measure of the LES simulation spread was chosen in part because the mean plus one standard deviation of the LWP for the entire
TABLE 3. Summary of numerical experiments.

\begin{tabular}{|c|c|c|c|c|}
\hline Model & $\begin{array}{c}\text { Experiment } \\
\text { A }\end{array}$ & $\begin{array}{c}\text { Experiment } \\
\text { B }\end{array}$ & $\begin{array}{l}\text { Precipitation } \\
\text { sensitivity }\end{array}$ & $\begin{array}{c}\text { Shallow } \\
\text { convection } \\
\text { sensitivity }\end{array}$ \\
\hline CCCma-UBC & $\mathrm{Y}$ & $\mathrm{Y}$ & $\mathrm{Y}$ & $\mathrm{Y}$ \\
\hline METO & $\mathrm{Y}$ & $\mathrm{Y}$ & $\mathrm{N}$ & $\mathrm{Y}$ \\
\hline RPN & $\mathrm{Y}$ & $\mathrm{Y}$ & $\mathrm{N}$ & $\mathrm{N}$ \\
\hline KNMI & $\mathrm{Y}$ & $\mathrm{Y}$ & $\mathrm{Y}$ & $\mathrm{N}$ \\
\hline NCAR-CAM & $\mathrm{Y}$ & $\mathrm{Y}$ & $\mathrm{Y}$ & $\mathrm{Y}$ \\
\hline CAM-UW & $\mathrm{Y}$ & $\mathrm{Y}$ & $\mathrm{Y}$ & $\mathrm{Y}$ \\
\hline NRL & $\mathrm{Y}$ & $\mathrm{N}$ & $\mathrm{N}$ & $\mathrm{N}$ \\
\hline NASA-LaRC & $\mathrm{Y}$ & $\mathrm{Y}$ & $\mathrm{Y}$ & $\mathrm{N}$ \\
\hline MPI & $\mathrm{N}$ & $\mathrm{Y}$ & $\mathrm{Y}$ & $\mathrm{N}$ \\
\hline ECMWF & $\mathrm{Y}$ & $\mathrm{Y}$ & $\mathrm{Y}$ & $\mathrm{Y}$ \\
\hline
\end{tabular}

group of LES simulations is a good proxy for the LES upper-quartile mean LWP. In these high-resolution simulations, all SCMs except KNMI and NASA-LaRC predicted $100 \%$ cloud cover, in agreement with observations. The KNMI and NASA-LaRC SCMs produced a cloud cover fraction as low as $80 \%$ within an hour. The rapid and unrealistic desiccation of the marine layer in the KNMI and NASA-LaRC simulations suggests overefficient entrainment in the presence of clouds in this case. Several LES models also predicted less than full cloud cover.

By the end of 6 simulation hours, the SCM-simulated LWPs span a quite large range, from about 12 to over $120 \mathrm{~g} \mathrm{~m}^{-2}$. The large spread in LWP in part reflects the sensitivity of liquid water content to small changes in total humidity and temperature induced by the different turbulent transport and microphysics schemes employed in the SCMs. It should be pointed out that NCAR-CAM and CAM-UW use the same cloud microphysics, and yet produce significant difference in LWPs, indicating that different turbulent transport realized in models is a more important factor than microphysics for causing the large LWP spread in this case. The SCM-mean LWP, however, is comparable to the observational estimate of $60 \mathrm{~g} \mathrm{~m}^{-2}$, which is slightly larger than the LES-mean LWP. Note that the range of LES-simulated LWPs is comparable to that of SCMs. Hence, as a group, LES models are still not accurate enough to usefully substitute for observations of MSC turbulence, entrainment, and cloud properties.

Figure 3 shows the profiles of $\theta_{l}, q_{t}, U$, and $V$ from experiment A averaged over the third and fourth simulation hours, the same period used for the LES intercomparison analysis. The $\theta_{l}$ and $q_{t}$ profiles from the high-resolution SCM simulations and LESs agree well with each other and with the observed mixed-layer structure. The observed inversion-capped mixed-layer structure shown in Fig. 1 is well simulated by all the SCMs. 
(a) Cloud cover fraction (\%), Experiment A

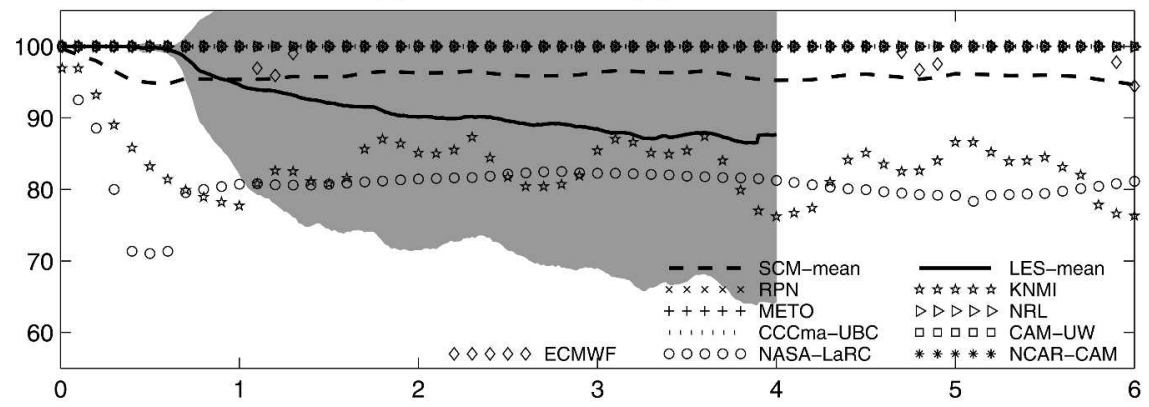

(b) Liquid water path $\left(\mathrm{gm}^{-2}\right)$, Experiment $\mathrm{A}$

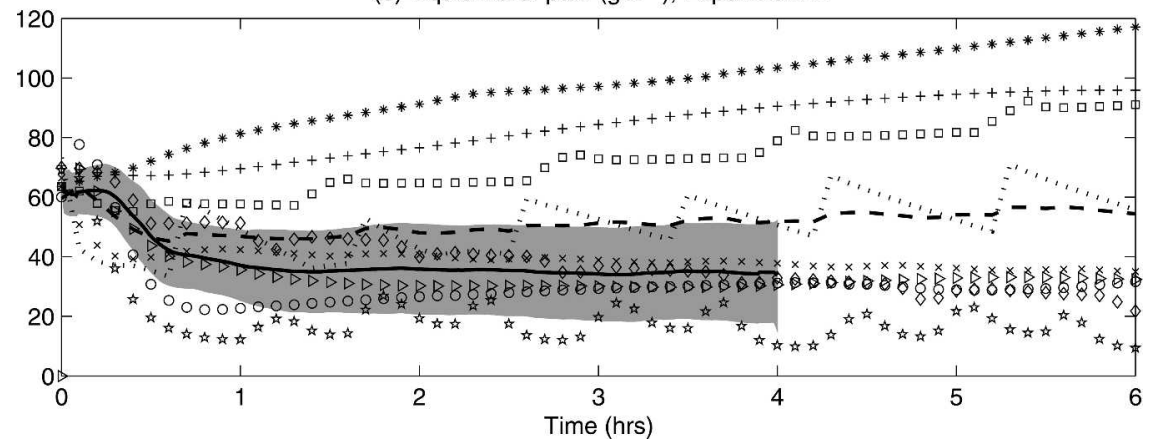

FIG. 2. Time series of total cloud cover fraction and vertical integrated liquid water path from experiment A. Gray shading indicates the $\pm 1 \sigma$ (standard deviation) range of the LES results.

Compared to the LES mean, some SCMs tend to smooth the sharp jumps a little at the cloud top and have larger gradients in $\theta_{l}$ and $q_{t}$ within the mixed layer. While these differences are subtle, they do affect LWP predicted by these SCMs for a given boundary layer mean height and thermodynamic properties. The SCM inversion structure depends on details of its turbulent mixing parameterization; some SCMs require an inversion transition layer several grid points deep, while others (e.g., with explicit entrainment parameterization) can produce inversions only a single grid layer thick.

One useful measure of internal thermodynamic gradients across the STBL, also discussed by STE, is the mixed-layer moisture difference $\delta q_{t}$ defined as

$$
\delta q_{t}=\int_{100 \mathrm{~m}}^{200 \mathrm{~m}} q_{t} d z-\int_{700 \mathrm{~m}}^{800 \mathrm{~m}} q_{t} d z
$$

Figure 4 shows a scatterplot of $\delta q_{t}$ against LWP for hours 3-4 along with their mean and standard deviation from LES and SCM. Except for NCAR-CAM (which will be discussed later), large LWP is correlated to small $\delta q_{t}$ (a particularly well mixed $q_{t}$ profile), presumably because this promotes higher $q_{t}$ within the cloud layer. Since all SCMs must pump the same surface moisture flux up through the boundary layer, eddy-diffusivity reasoning suggests that small $\delta q_{t}$ (as observed) should be associated with vigorous turbulent mixing across the STBL.

STE showed that some LES models produced larger $\delta q_{t}$ in association with marginal decoupling of the boundary layer turbulence into separate cloud and subcloud turbulent layers with a cloud-base minimum in vertical velocity variance. A similarly simple interpretation does not carry over to SCMs. Their diverse turbulence parameterizations allow $\delta q_{t}$ to vary between models for many reasons, including formulations for turbulent length-scale, turbulence production in partly or fully cloudy conditions, turbulent transport, and nonlocal flux-gradient relations.

The horizontal wind profile shown in Fig. 3 evolves substantially in the boundary layer from its initial geostrophic specification and shows some spread across SCMs. Both SCM-mean $U$ and $V$ have a noticeable bias compared with the LES-mean wind profiles. This may reflect inadequate SCM treatment of momentum transport, as well as the non-steady state of boundary layer winds in SCM simulations. The wind profiles from all SCMs are still evolving substantially after $3 \mathrm{~h}$, a time when most LES models have reached a quasi steady state. Note that the plotted mean $U$ and $V$ profiles do not include the CCCma-UBC results, which specified 

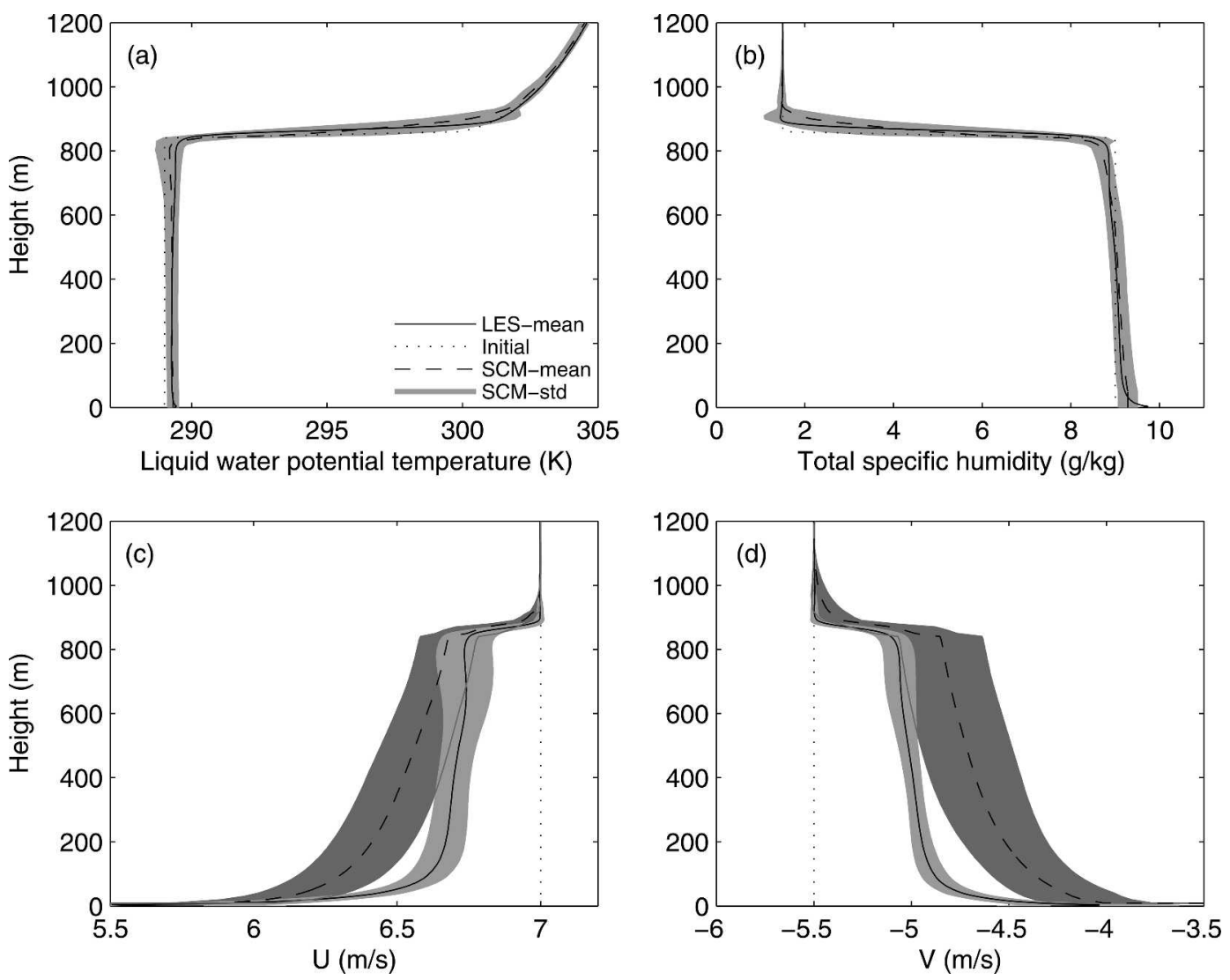

FIG. 3. Mean profiles of liquid water potential temperature, specific humidity, and horizontal winds averaged over 3-4 simulation hours from experiment A. Dashed line is the average of SCMs. Solid line is the result from LES (STE). Dotted line delineates the initial state. Light and dark shading indicate the $\pm 1 \sigma$ ranges of inter-LES and inter-SCM profiles, respectively.

constant winds (equal to the geostrophic winds) throughout the simulation. Note that in this experiment, there is little potential impact of wind biases on thermodynamic fields since the surface fluxes are specified and the TKE production is dominated by buoyancy rather than shear.

Figure 5 shows the profiles of $q_{l}$ averaged over 3-4 simulation hours, which vary substantially between models to create the LWP variations seen in Fig. 2. Like LWP, the $q_{l}$ profile is sensitive to the small changes in $\theta_{l}$ and $q_{t}$ caused by different turbulence schemes. In most SCMs, $q_{l}$ increases with height up to a maximum very near cloud top similar to what is shown in observations (Fig. 1). One exception is the CCCma-UBC simulation, in which $q_{l}$ reaches its maximum somewhere in the upper part of the cloud layer. This is associated with the technique used to calculate the nonlocal diffusivity, which employs relaxation toward a well-mixed reference state. Several SCMs predict a subadiabatic increase of $q_{l}$ with height and a smaller maximum $q_{l}$ than was observed. The NCAR-CAM model has a secondary $q_{l}$ maximum near $400 \mathrm{~m}$, which appears to be an artifact of its cloud microphysics scheme. In contrast, the ECMWF SCM produces a superadiabatic $q_{l}$ gradient, generating the observed $q_{l}$ maximum, but only half as thick as observations.

The simulated STBL evolution is heavily influenced by the boundary layer entrainment rate. For those models in which explicit entrainment parameterization is employed, the entrainment rate $W_{e}$ is readily obtained, while for others, it must be inferred indirectly, for example, from the simulated inversion rise rate via

$$
W_{e}=\frac{d z_{i}}{d t}+D z_{i}
$$

The simulated boundary layer top is diagnosed as the height at which $q_{t}=8 \mathrm{~g} \mathrm{~kg}^{-1}$ based on a linearly interpolated $q_{t}$ profile between grid levels. Its evolution in experiment A is plotted in Fig. 6.

Over simulation hours 2-6, SCMs predicted an inversion rise rate $d z_{i} / d t$ in a range of $0.3-0.5 \mathrm{~cm} \mathrm{~s}^{-1}$, which 


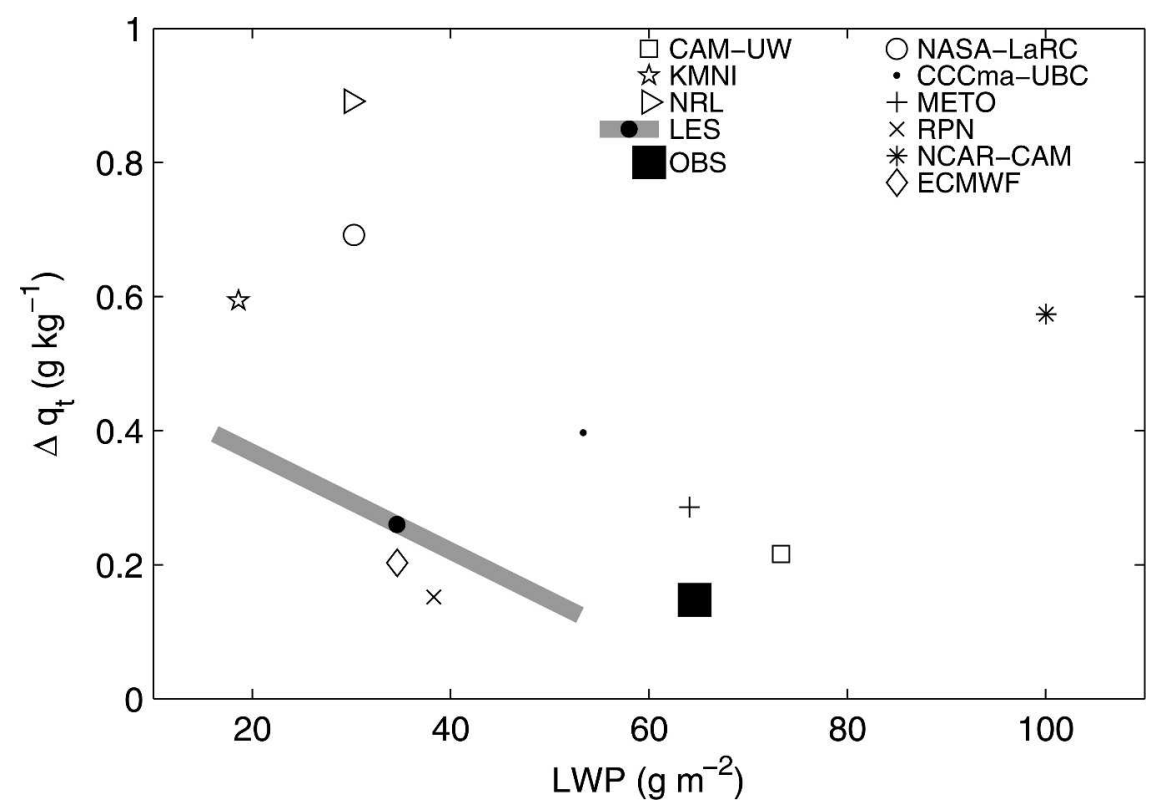

FIG. 4. Correlation between moisture difference in the mixed-layer $\delta q_{t}$ and LWP for hours 3-4 from experiment A. Gray shade indicates the range of LES. Filled square box denotes observations.

is very close to observations (Stevens et al. 2003b), and LESs (STE) near $0.4 \mathrm{~cm} \mathrm{~s}^{-1}$. These small rise rates in most SCMs and LESs were consistent with the observed rough balance between entrainment and large- scale subsidence $D z_{i} \approx 0.32 \mathrm{~cm} \mathrm{~s}^{-1}$. Compared with observations and other SCMs, the ECMWF inversion rise rate is notably fast. This is most likely caused by its entrainment calculation, which is highly sensitive to nu-

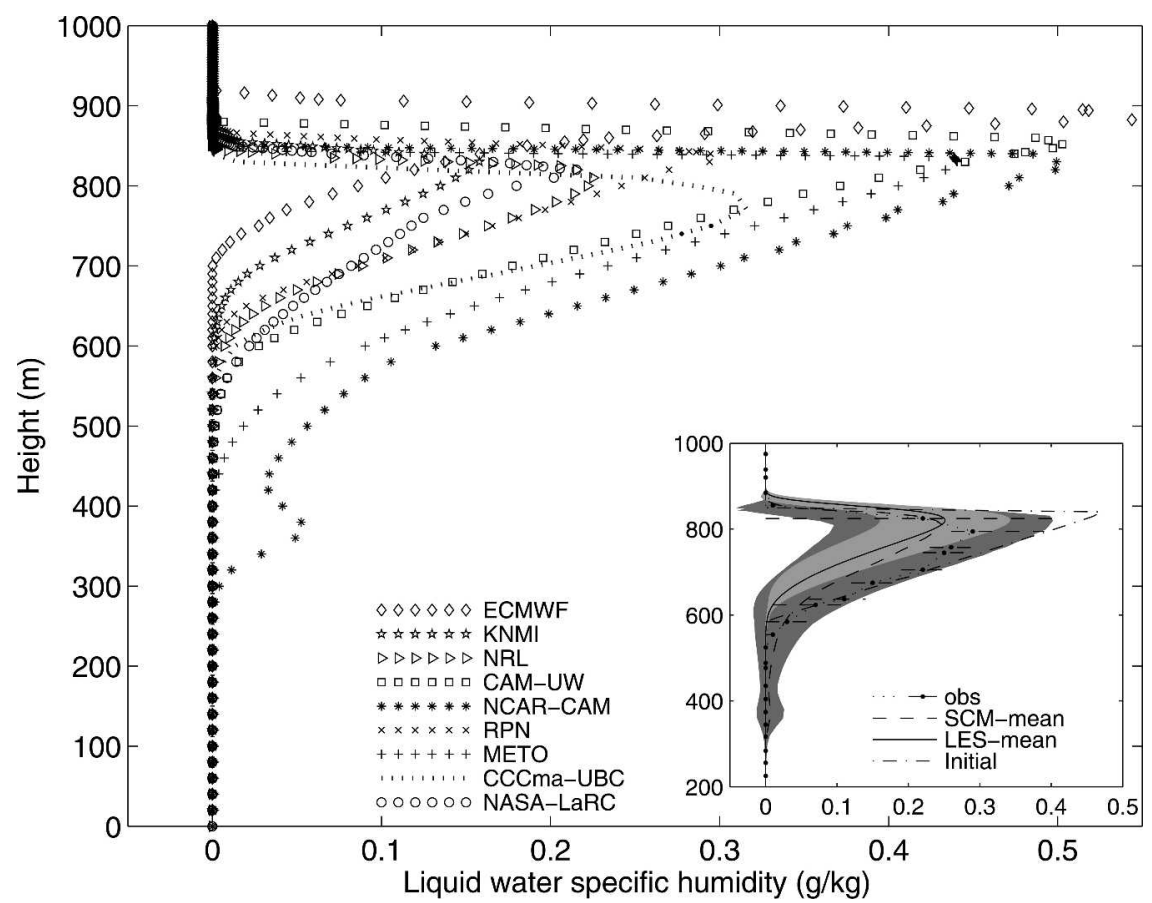

FIG. 5. Mean profiles of liquid water specific humidity averaged over 3-4 simulation hours by SCMs from experiment $\mathrm{A}$. The embedded figure at the right-bottom corner shows the SCM-mean and LES-mean $q_{l}$ profiles and their $\pm 1 \sigma$ ranges (shading) along with observed values and initial profiles. 


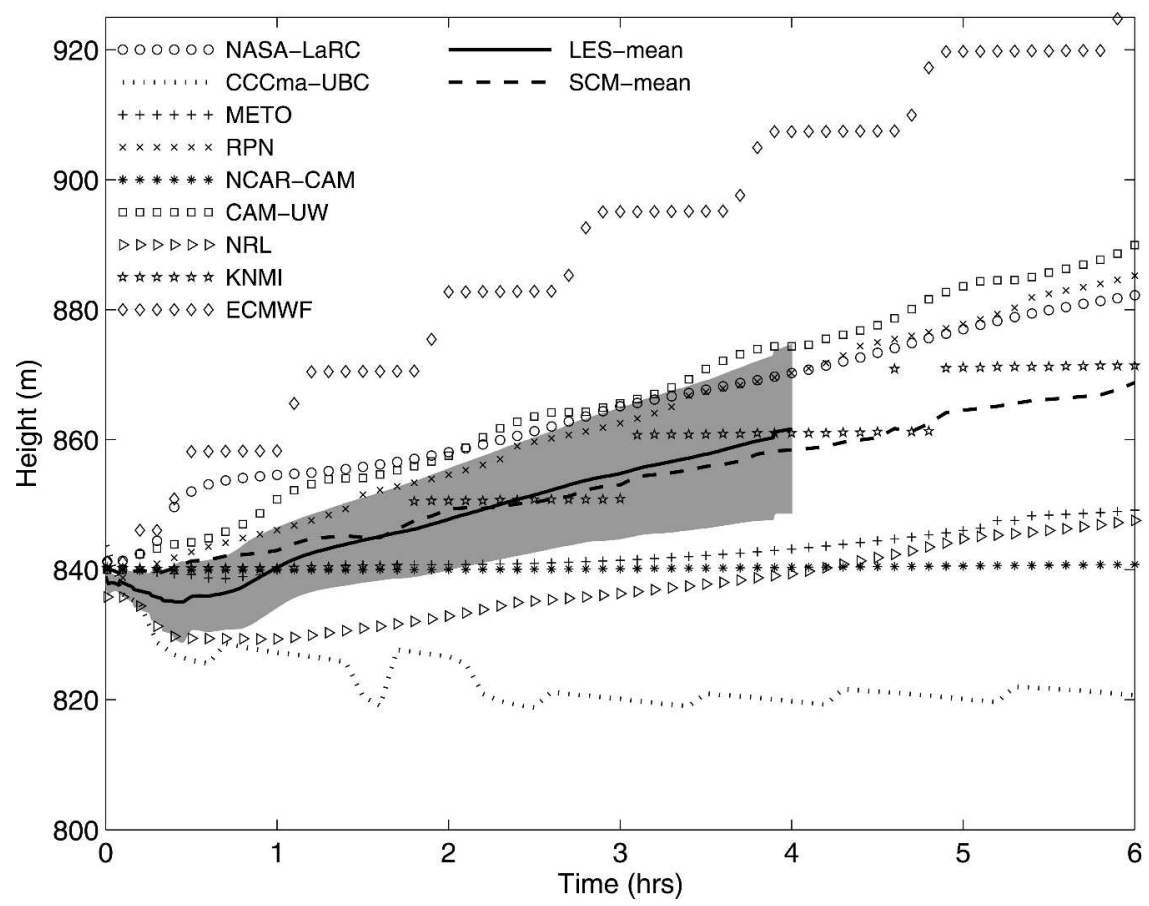

FIG. 6. Time evolution of the simulated boundary layer top from experiment A. Shading indicates the $\pm 1 \sigma$ ranges of LES results.

merical discretization around the inversion. This problem could be solved by using the method proposed by Lock (2001) and Grenier and Bretherton (2001).

Table 4 lists the resulting hours 2-6 mean entrainment rates deduced from (6), as well as the observational and LES estimates. The entrainment rates estimated from experiment B (to be discussed shortly) are also listed in the table. The consistency of $W_{e}$ between most models and observations is comparable to that documented in Duynkerke et al. (2004) and is an improvement from the earlier GCSS study of Bechtold et al. (1996). This consistency in $W_{e}$ may result from both careful case specification and parameterization improvements. The latter is evident from the consistency between the calculated $W_{e}$ from Eq. (6) and the predicted rate from those models, such as METO, CAMUW, and ECMWF, which employ the explicit entrain- ment parameterization (not shown here). In contrast to broadly consistent $W_{e}$, SCM-simulated LWPs show a large spread at hour 6 . This partly reflects the rapid transient evolution of inversion structure and LWP during hour 1, when several models undergo up to a fourfold LWP decrease.

It may seem paradoxical that $W_{e}$ varies much less between SCMs than LWP, given the central role of entrainment in the evolution of mixed-layer properties. One perspective considers the feedbacks between the entrainment rate, thermodynamic state of STBL, and cloud properties illustrated by Fig. 7. In each SCM simulation, the parameterized entrainment process is sensitive to cloud liquid water through its impact on turbulence via mixing-induced evaporative cooling and radiative fluxes. This is indicated in Fig. 7 as an arrow from LWP to $W_{e}$. Meanwhile, $W_{e}$ slowly affects the

TABLE 4. SCM-derived entrainment rates and observational and LES estimates. Unit is $\mathrm{cm} \mathrm{s}^{-1}$.

\begin{tabular}{|c|c|c|c|c|c|c|c|c|c|c|c|c|}
\hline & $\begin{array}{l}\text { NASA- } \\
\text { LaRC }\end{array}$ & $\begin{array}{c}\text { CCCma- } \\
\text { UBC }\end{array}$ & METO & RPN & $\begin{array}{l}\text { NCAR- } \\
\text { CAM }\end{array}$ & $\begin{array}{l}\text { CAM- } \\
\text { UW }\end{array}$ & KNMI & NRL & MPI & ECMWF & $\mathrm{OBS}^{\mathrm{a}}$ & LES \\
\hline Expt A $(2-6$ h) & 0.47 & 0.27 & 0.38 & 0.54 & 0.32 & 0.54 & 0.47 & 0.42 & & 0.68 & & $0.50 \pm 0.10^{\mathrm{b}}$ \\
\hline Expt B (2-6 h) & 0.35 & 0.29 & 0.29 & 0.33 & 0.36 & 0.37 & 0.33 & & 0.36 & 0.28 & $0.40 \pm 0.08$ & $0.47^{\mathrm{c}}$ \\
\hline Expt B $(2-36$ h) & 0.44 & 0.31 & 0.39 & 0.32 & 0.34 & 0.35 & 0.33 & & 0.39 & 0.47 & & $0.46^{\mathrm{c}}$ \\
\hline
\end{tabular}

a OBS: Observations.

${ }^{\mathrm{b}}$ LES mean.

${ }^{\mathrm{c}}$ UCLA-LES. 


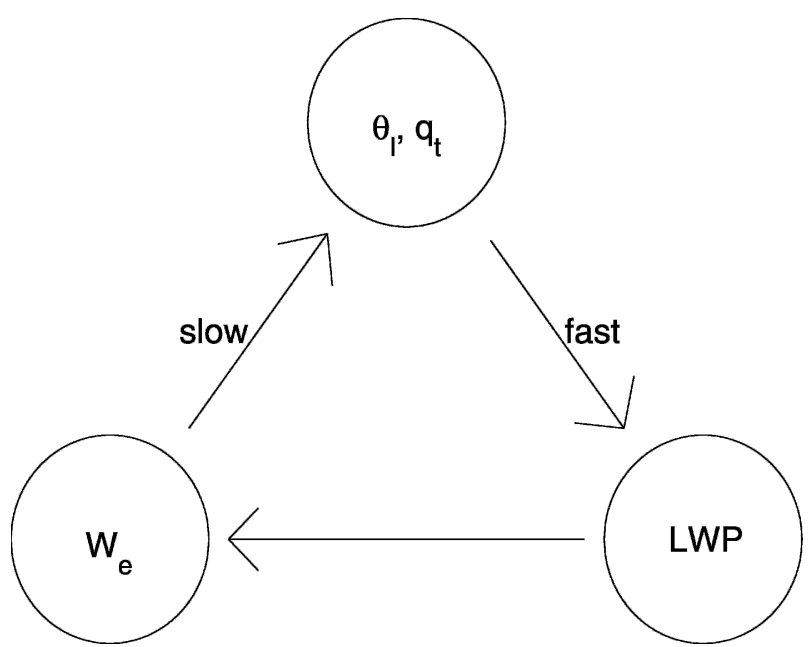

FIG. 7. Schematic illustration of feedbacks among $W_{e}$, LWP, and $\theta_{l}$ and $q_{t}$.

evolution of the mixed-layer profiles of $\theta_{l}$ and $q_{t}$ (left arrow in Fig. 7). Since even a small change in $\theta_{l}$ and $q_{t}$ can result in a substantial variation in liquid water content (right arrow in Fig. 7), the LWP rapidly evolves toward an equilibrium value that sustains roughly enough entrainment to keep LWP at a nearly steady state. As discussed by Bretherton and Wyant (1997), this forces the STBL toward approximate moisture and energy balance between entrainment warming, radiative cooling, and surface fluxes. Since the surface fluxes are fixed, as is the radiative cooling as long as the cloud remains optically thick, all SCMs maintain similar entrainment warming, and hence similar equilibrium $W_{e}$, but with subtly different $\theta_{l}$ and $q_{t}$ profiles that produce considerably different cloud properties. This energy balance and hence the equilibrium $W_{e}$ can be changed if the cloud is excessively thinned (as in the KNMI model) or if there are large numerical errors in treating entrainment process at cloud top (Lenderink and Holtslag 2000), as appears to occur in the ECMWF SCM.

Some participating SCMs are capable of maintaining the persistent clouds observed in this case, while others are not, although the CTEI criterion is met in all simulations. For example, the KNMI and NASA-LaRC models simulate partial cloud breakup in response to a parameterized form of CTEI through inversion TKE$W_{e}$ feedback and the negative feedback via radiative forcing; that is, thinning clouds correspond to the decrease of longwave cooling and the reduction of buoyancy, which leads to a further desiccation of the marine layer.

\section{b. Experiment $B$}

The first focus of experiment $B$ is the extent to which coarse operational resolution affects the simulation of bulk cloud layer properties such as the LWP, cloud cover fraction, and mean thermodynamic profiles. The second focus is the long-term evolution of the SCMs subject to constant forcings.

Figure 8 shows the time evolution of SCM-produced total cloud cover fraction and integrated LWP from experiment $\mathrm{B}$, along with those predicted by UCLALES. Even in the first $6 \mathrm{~h}$ cloud fractions show a larger spread among SCMs than in experiment A. One might blame this on the interactive formulation of the surface fluxes in this experiment. However, the surface fluxes computed interactively agreed fairly well across SCMs (Fig. 9), though the SCM-predicted surface latent heat fluxes and sensible heat fluxes are generally larger and smaller, respectively, than those of UCLA-LES, and do drift over $48 \mathrm{~h}$ from the prescribed values of experiment A. Thus, most intermodel variability in cloud properties must be due to the differences between cloud and turbulence schemes and in particular their numerical implementations, aggravated by coarse resolution.

Some SCMs such as RPN, NASA-LaRC, and NCAR-CAM predicted a lower cloud cover fraction in this experiment. The RPN SCM, an extreme case, produced $100 \%$ cloud cover in the high-resolution simulation, but less than $40 \%$ within a hour of simulation at coarse resolution, perhaps a consequence of its statistical cloud scheme applied to a vertically underresolved cloud layer or its vertical cloud overlap assumptions. However, like UCLA-LES, the CCCma-UBC, CAMUW, MPI, and METO SCMs are still able to produce approximately $100 \%$ cloud cover in the coarseresolution simulations.

Most SCMs produced 3-6-h average LWPs in experiment B, broadly comparable to experiment A (Fig. 10). The most extreme exception is the NCAR-CAM simulation in which LWP drops fourfold compared to the high-resolution simulation. In section $3 c$, we show this results from the shallow convection scheme employed in the model. The NASA-LaRC and RPN models also have rather lower LWP in experiment B, consistent with their lower cloud cover fraction.

It is worth comparing LWPs in NCAR-CAM and CAM-UW simulations since the difference is solely resulted from turbulence and shallow convection schemes. Figures $2 \mathrm{~b}$ and $8 \mathrm{~b}$ show that CAM-UW generated an LWP close to $80 \mathrm{~g} \mathrm{~m}^{-2}$ in the first 6-h simulations in both experiments A and B. Sensitivity tests shown in section $3 \mathrm{c}$ indicate that the shallow convection scheme (ZB; BZ) employed in CAM-UW has little effect on LWP. The insensitiveness of LWP to the model vertical resolution shown in experiments $\mathrm{A}$ and $\mathrm{B}$ implies the robustness of the CAM-UW moist turbulence scheme (Grenier and Bretherton 2001; BZ; ZB) in rep- 
(a) Cloud cover fraction (\%), Experiment B

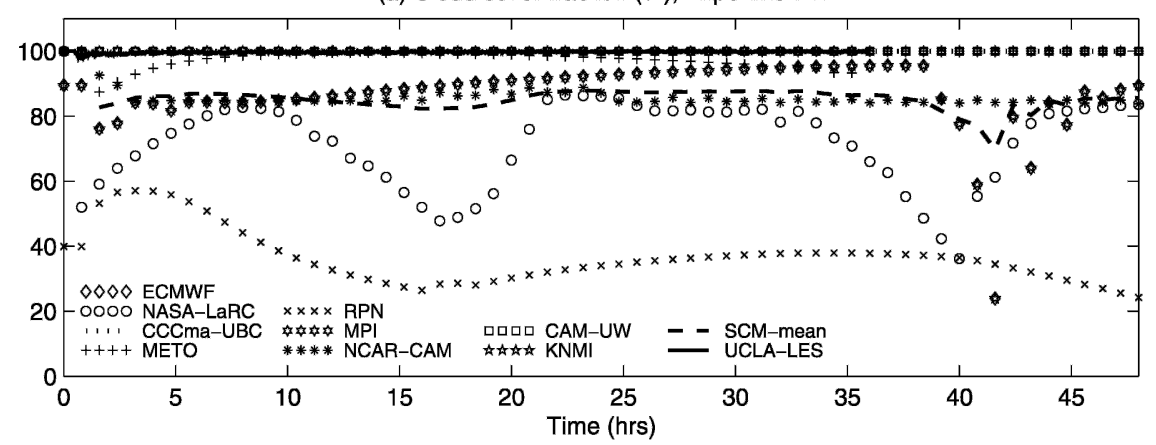

(b) Liquid water path $\left(\mathrm{gm}^{-2}\right)$, Experiment $\mathrm{B}$

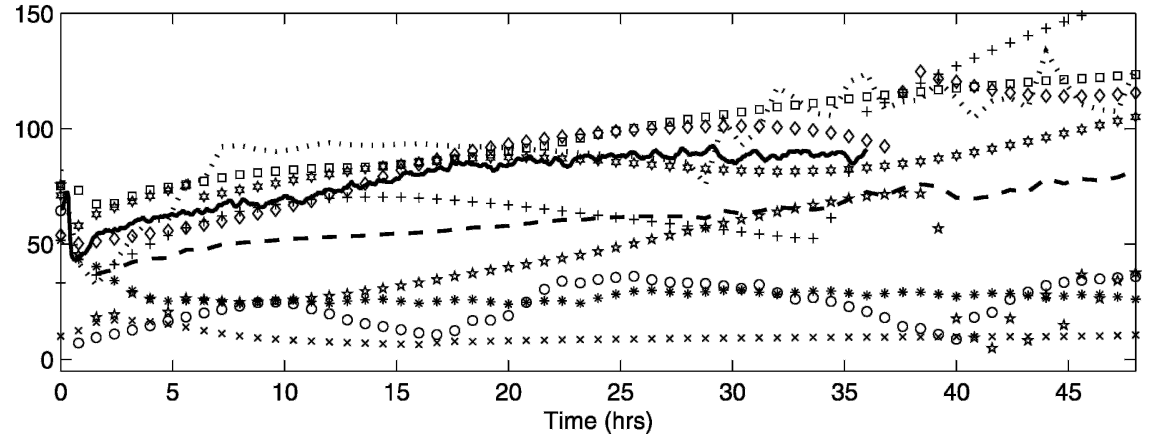

FIG. 8. Time series of total cloud cover fraction and vertical integrated liquid water path from experiment $\mathrm{B}$.

resenting MSC cloud fields. In contrast, the NCARCAM simulations show a marked sensitivity to the model vertical resolution. LWPs drop more than sixfold from experiment A to experiment B. Sensitivity tests shown later further indicate that the NCAR-CAM shallow convection scheme (Hack 1994) plays a significant role in determining LWP, suggesting that the NCARCAM dry turbulence scheme (Holtslag and Boville 1993) alone is not sufficient in representing MSC cloud fields although it may predict a similar entrainment rate to that of CAM-UW.

Compared with Fig. 2b, the long-term evolution of LWPs from different SCMs shows even more variability, as seen in Fig. 8b. In particular, even though the SCM-mean LWP is similar between experiments A and $\mathrm{B}$, in B the models split after $6 \mathrm{~h}$ into one group with consistently high LWP of $75-140 \mathrm{~g} \mathrm{~m}^{-2}$ and another equally sized group with low LWP of $5-50 \mathrm{~g} \mathrm{~m}^{-2}$. This might be caused by the setup of experiment $\mathrm{B}$, which leads to long-term drifts of temperature above the inversion due to radiative-subsidence imbalance as evidenced in temperature profiles shown in Fig. 11. Therefore, SCMs cannot be run to a steady state under the setup of experiment B. It might be enlightening to formulate future SCM intercomparisons designed to focus on the predicted STBL properties in simulations run to a near-equilibrium state.
As in experiment $A$, the long-term variation in LWPs shown in experiment B (Fig. 8b) is barely correlated to the mean entrainment rates of hours 2-36 listed in Table 4. For example, in the low LWP group, NASALaRC predicted a larger $W_{e}$ as one would expect, but RPN and KNMI produced a smaller $W_{e}$. Comparisons between hours 2-6 entrainment rates further indicate that there is little correlation between the $W_{e}$ predicted by a high-resolution simulation and its operationalresolution counterpart. For instance, the ECMWF SCM has the lowest $W_{e}$ at operational resolution despite having the highest $W_{e}$ at high resolution. This corroborates the perspective of Fig. 7 that the LWP adjusts in a model- and resolution-dependent fashion to a strong model-independent energy-balance constraint on $W_{e}$.

Figure 11 shows the mean profiles of $\theta_{l}, q_{t}$, and $q_{l}$ at 3-4 and 35-36 h predicted by various SCMs from experiment B compared with those of UCLA-LES. At 3-4 h, all SCM simulations and LES still reflect the initial $\theta_{l}$ and $q_{t}$ in the mixed layer. The inversion-layer structure and $q_{l}$ profiles are no longer well resolved by SCMs, and differ between models due to the different model grid levels and the mixing parameterizations. The coarse-resolution models produce a lower peak of $q_{l}$ compared with the high-resolution simulations, but generally spread $q_{l}$ over a broader height range to 
(a) Surface latent heat flux $\left(\mathrm{W} / \mathrm{m}^{2}\right)$

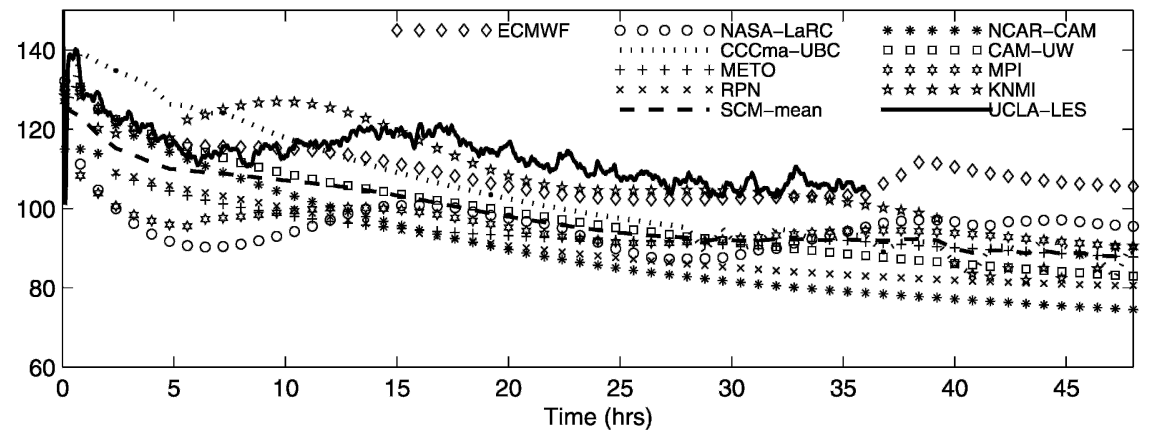

(b) Surface sensible heat flux $\left(\mathrm{W} / \mathrm{m}^{2}\right)$

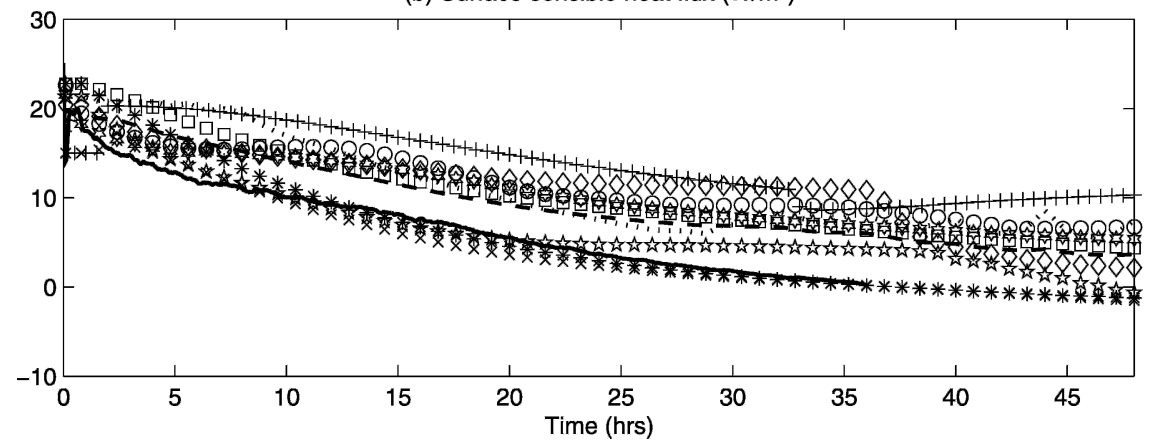

FIG. 9. Time variation of the simulated surface latent and sensible heat fluxes from experiment B.

achieve LWP comparable to the high-resolution simulations shown in Fig. 10. Overall, the mixed-layer thermodynamic structure predicted by the LES is also simulated by most SCMs, though with larger vertical $q_{t}$ gradients.

Figures 11d-f show that after $35 \mathrm{~h}$, the simulated profiles, especially $q_{l}$, differ more between SCMs. More surprisingly, the LES cloud top (1025 m) is actually above the range of the SCM predictions. This implies a slightly stronger entrainment rate in the LES than in the SCMs, although its LWP was above the SCM median value shown in Fig. 8. This LWP could be sustained in the LES despite the dry boundary layer associated with this stronger entrainment, since the LES generated a sharp-topped adiabatic cloud layer and a more precisely well mixed $q_{t}$ profile than most SCMs.

Although all SCMs maintain a fairly well mixed boundary layer below $600 \mathrm{~m}$, there is some spread in the mean mixed-layer moisture, which may be attributed partially to the different surface moisture fluxes shown in Fig. 9, but mainly to different rates of entrainment drying. This is evident from the averaged entrainment rates of hours 2-36 listed in Table 4, which have a larger range than those of hours 2-6. For example, the boundary layer deepened much faster and stayed much drier in the NASA-LaRC simulation than in the
CCCma-UBC simulation despite the similar surface fluxes. The LES, with strong entrainment, produces the driest mixed-layer moisture despite its relatively high surface moisture flux. However, there is still little correlation between the nearly 36-h-averaged entrainment rate and the hours 35-36 LWP. A more vigorously entraining STBL will have a higher cloud base because it is drier, but also a higher cloud top. Instead, as in the high-resolution simulations, each SCM adopts a different cloud and inversion structure to maintain roughly the same energy-balancing $W_{e}$. For instance, the RPN simulation has a slightly lower than average entrainment rate, yet the smallest hours 35-36 $q_{l}$ and LWP of all models. Figures 11d-f suggest that this is associated with a "rounded-off" inversion zone that fills two contiguous layers, in which cloud could otherwise form, coupled to a turbulence scheme that allows this STBL structure to entrain vigorously despite the dearth of clouds.

\section{c. Sensitivity to precipitation and shallow convection}

As marine stratocumulus thickens, drizzle may also become important in the water budgets and turbulent dynamics through latent heating in the cloud layer and subcloud evaporative cooling. The RF01 intercompari- 


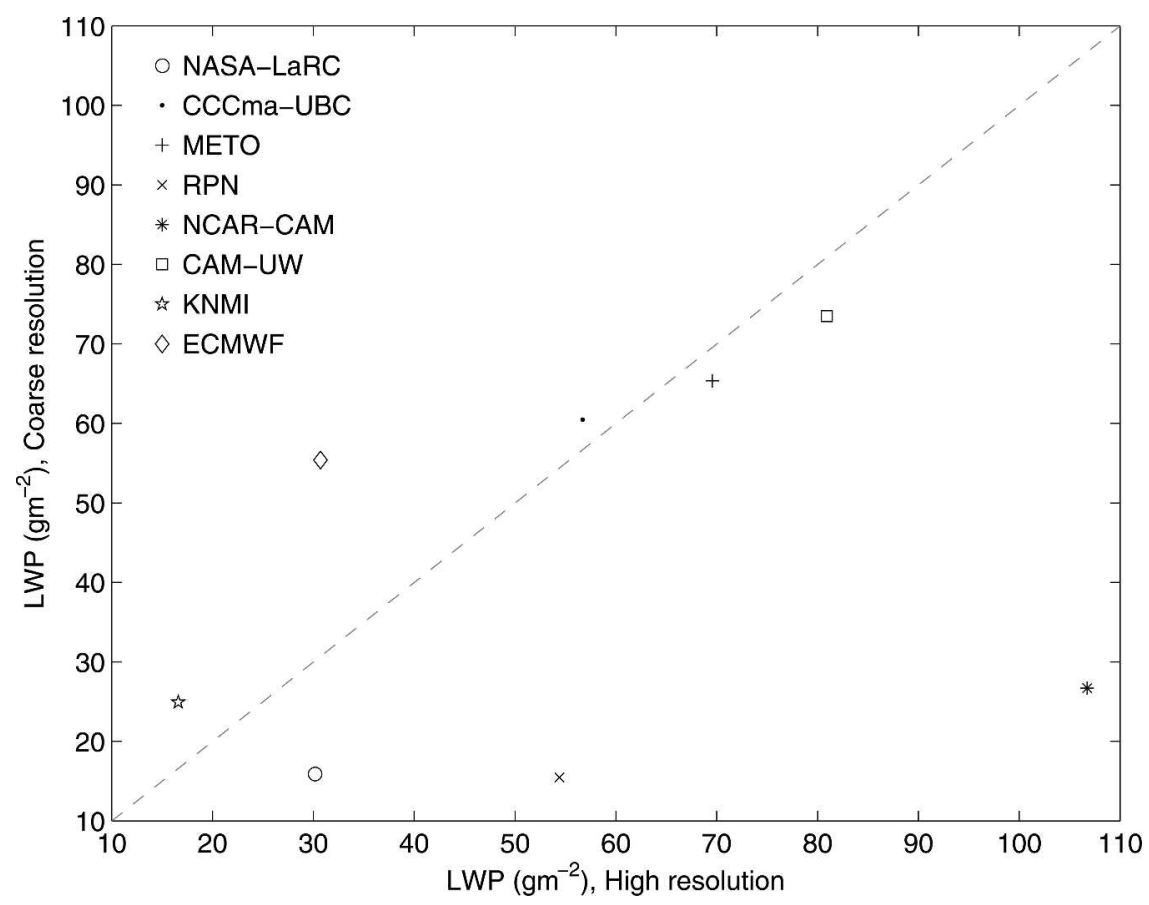

FIG. 10. Comparison of the averaged LWP from 3-6 simulation hours between experiments $\mathrm{A}$ and $\mathrm{B}$.

son was chosen in part because of the observed lack of drizzle, but it is nevertheless possible that in some SCMs drizzle may significantly affect the simulated LWP and STBL structure. Because of the difficulties in separating precipitation from other processes in some models, only NASA-LaRC, CCCma-UBC, NCARCAM, CAM-UW, KNMI, and ECMWF SCMs executed the precipitation sensitivity tests at both high and coarse resolutions, while the MPI SCM did only the coarse resolution sensitivity test. For all SCMs, in experiment $\mathrm{A}$, the simulated thermodynamic structure of STBL and its associated cloud fields are barely affected by parameterized precipitation. In experiment $B$, no significant change in cloud cover in response to precipitation was simulated by any SCMs, but a weak influence of precipitation on LWP was found in some SCMs. Table 5 lists the LWP with and without parameterized precipitation microphysics averaged over $40-48 \mathrm{~h}$ from experiment B. The CCCma-UBC, NCAR-CAM, CAM-UW, MPI, and ECMWF simulations predicted small precipitation fluxes that reduced LWP between $6 \%$ and $28 \%$, while in the NASA-LaRC and KNMI simulations, no precipitation was simulated at all.

The weak influence of simulated precipitation on MSC cloud properties shown in this case appears to conflict with other simulations (e.g., Wang et al. 1993) that have found larger effects of suppressing precipitation on MSC cloud cover. This is to be expected since our simulations are based on a nonprecipitating case. An upcoming GCSS WG1 intercomparison will focus on an STBL in which substantial precipitation was observed.

We also performed a sensitivity study of the effects of parameterized shallow cumulus convection on the STBL simulation. Because of the diverse parameterizations for convective triggering, the shallow cumulus convection scheme in a SCM may activate in regimes where there is no shallow convection in reality. Among all the participating SCMs, CCCma-UBC, METO, NCAR-CAM, CAM-UW, and ECMWF executed this sensitivity test. In both high and coarse resolution, the simulations by the METO, CAM-UW, and ECMWF SCMs show little sensitivity to their shallow convection schemes. The other two models, NCAR-CAM and CCCma-UBC, also show an insignificant influence of the shallow convection scheme on the STBL in the high-resolution simulations, but a substantial influence of the convection scheme is found in their coarseresolution simulations, as shown in Fig. 12. The NCARCAM simulations show an enormous sensitivity to its shallow convection scheme. Without the shallow convection scheme, the coarse-resolution NCAR-CAM produces an unrealistically thick cloud layer almost touching the ground, indicating that the boundary layer scheme does not generate sufficient turbulence to transport moisture upward efficiently. We speculate 

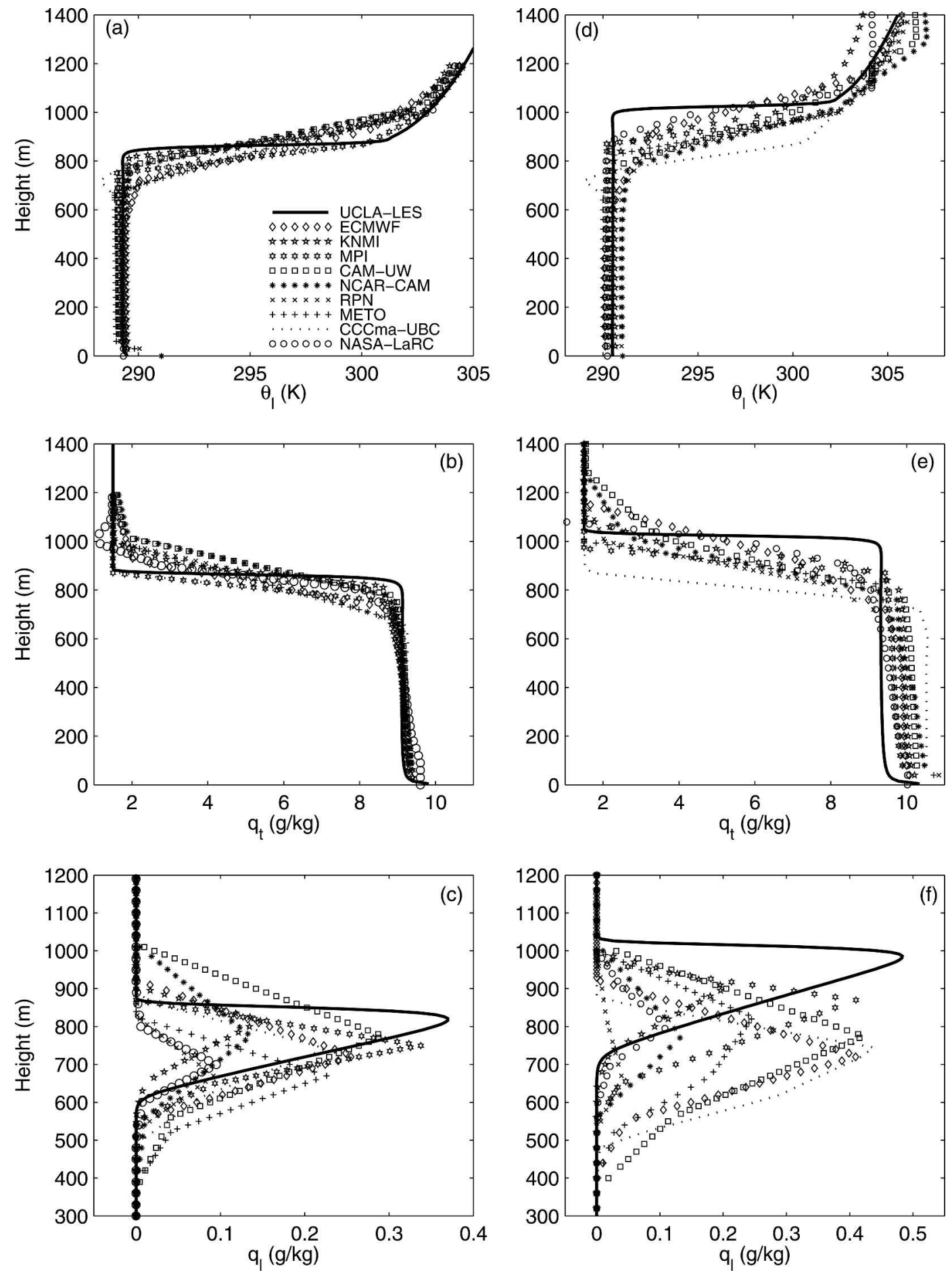

FIG. 11. Mean profiles of liquid water potential temperature $\theta_{l}$, total specific humidity $q_{t}$, and liquid water specific humidity $q_{l}$ simulated by different SCMs and the UCLA-LES from experiment B. Profiles averaged over (left) 3-4 and (right) 35-36 simulation hours, respectively.

that the turbulent mixing scheme used in NCAR-CAM tends to produce a colder than realistic cloud layer with larger LWP and smaller entrainment rate. Since this bias disappears at high resolution, it might be address- able by reformulating the NCAR-CAM boundary layer height diagnosis. In contrast, turning on the shallow convection scheme increases LWP about $50 \%$ in the CCCma-UBC simulations. One possible reason for this 
TABLE 5. Hours 40-48 mean LWP $\left(\mathrm{g} \mathrm{m}^{-2}\right)$ from coarse-resolution simulations.

\begin{tabular}{lccccccc}
\hline \hline & CCCma-UBC & NCAR-CAM & CAM-UW & NASA-LaRC & MPI & KNMI & ECMWF \\
\hline Precipitating & 89.4 & 20.1 & 113.6 & 28.6 & 89.3 & 20.8 & 93.0 \\
Nonprecipitating & 113.5 & 27.7 & 120.6 & 28.6 & 96.4 & 20.8 & 115.6 \\
\hline
\end{tabular}

increase of LWP suggested by Lenderink and Holtslag (2004) is that the convection scheme tends to produce liquid water through its detrainment process at the top of clouds.

The appropriate coupling between the boundary layer scheme and shallow convection scheme is not just an issue for correctly simulating the STBL. It becomes more important in the transition from stratus deck regime to trade wind cumulus regime where the interaction between stratiform and convective clouds is the key to determine the thermodynamic structure, cloud cover, and air-sea fluxes in this region.

\section{Summary}

Accurate simulation of marine boundary layer clouds presents a long-standing challenge to climate modeling and climate change prediction. This GCSS WG1 intercomparison study has assessed how well a nonprecipitating marine nocturnal stratocumulus-topped mixed- layer structure can be reproduced by SCMs. Ten SCMs were intercompared using a case based on observations from DYCOMS-II RF01. Although this is an idealized STBL case, the initial and forcing conditions are specified in such a way that the important observed features of STBL can be best represented by LESs after reaching quasi steady state. For this reason, the comparison between SCM simulations and the available observations from field experiments provides an excellent way to assess the current model's ability in representing nonprecipitating STBL, and such an assessment should not be affected substantially due to the specific case specification used in this study. To better separate the effects of vertical resolution and physical parameterizations, two experiments were executed. In the first experiment, a 6-h simulation with all models configured to $10-\mathrm{m}$ grid resolution was forced by the specified surface fluxes and compared with observations and a companion study using a suite of similarly forced LES models (STE). In the second experiment, operational reso-

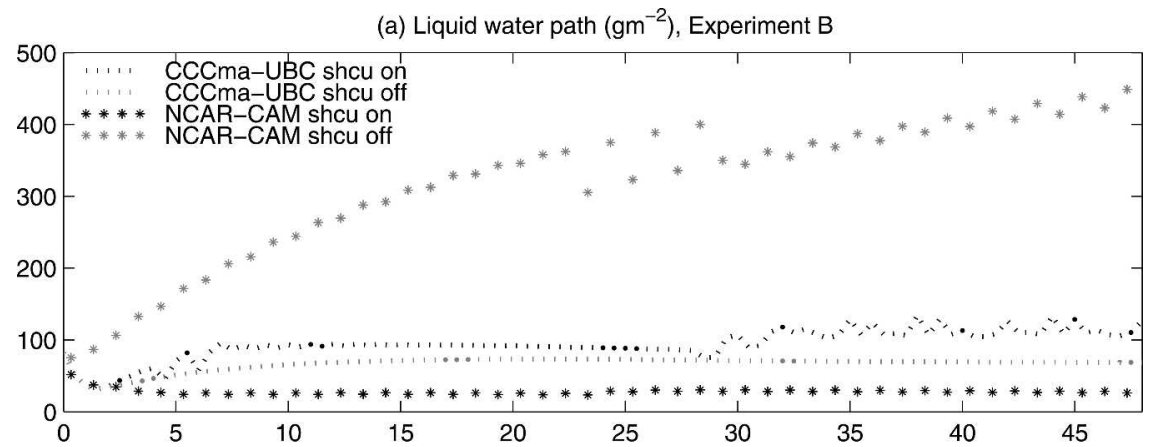

(b) Cloud cover fraction (\%), Experiment B

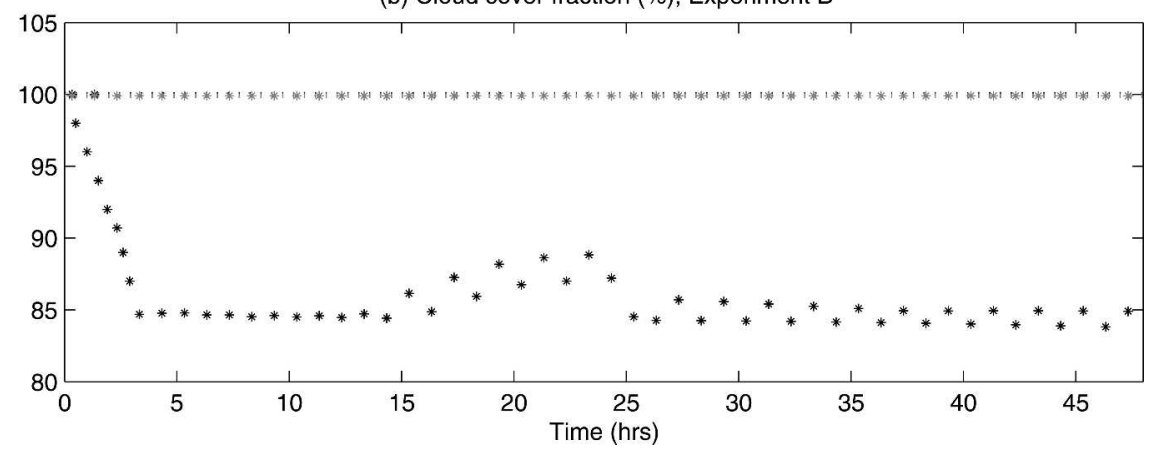

FIG. 12. Time variation of liquid water path and cloud cover fraction simulated by SCMs with shallow convection scheme turned on and off from experiment B. 
lution and a specified SST were used for a 48-h simulation. In both experiments the same formulation was used by all SCMs to calculate radiative cooling, so that the difference in simulations arising from radiative forcing was reduced to the minimum.

Given appropriate initial conditions and forcings, all SCMs are able to produce and maintain a mixed STBL capped by a sharp inversion similar to observations and LESs in simulations with a high vertical resolution comparable to LES, though the simulated moisture profiles show a slight gradient in the mixed layer. However, within an hour of simulation, the SCMs disagree markedly on their predicted cloud water content and LWP. There is a nearly 10-fold variation in the LWP among SCMs, although the averaged LWP over all models agrees well with observations and LESs.

In operational-resolution simulations, it is not possible for SCMs to simulate the observed sharp inversion. As a result, SCMs tend to underpredict cloud water content. However since they usually also overpredict cloud thickness at the same time, such a compensation leads to an integrated LWP (and hence cloud radiative properties) similar to that from highresolution simulations.

Remarkably, almost all SCMs predicted entrainment rates within $30 \%$ of observational estimates regardless of resolution, an apparent improvement from SCM intercomparisons 5-10 yr ago (e.g., Bechtold et al. 1996). Perhaps this is due partly to more experience with case specifications, but it is corroborated by recent improvements in representing subtropical boundary layer clouds in large-scale models (e.g., Martin et al. 2000). These improvements include a better representation of a wide variety of turbulence and cloud descriptions and more careful attention to the interaction of relevant assumptions and their numerical representation. However, our simulations indicate that the improved entrainment rate estimates do not similarly improve predicted LWP and cloud radiative properties.

A sensitivity test of the inclusion of parameterized precipitation processes showed little effect on cloud cover and only a weak influence on LWP in some SCMs. This is as hoped for this essentially nonprecipitating case. However, this result does not imply that current microphysics and turbulence parameterization are good enough to appropriately represent thicker or less cloud condensation nucleus-rich stratocumulus layers when drizzle is significant. Another sensitivity test indicated that improper triggering of the shallow cumulus convection scheme in some models can appreciably (but unrealistically) affect a stratocumulus-topped mixed layer. Careful design of microphysics and cumu- lus convection schemes that can function properly together with boundary layer turbulence schemes is a continuing climate model parameterization issue for which SCM simulations and GCSS-style intercomparisons are powerful tools for progress.

This study suggests that a considerable progress of representing STBL in large-scale models has been made over the last decade owing to the improvements in turbulence and cloud parameterizations. However, the large continued intermodel variability in LWP in our current intercomparison suggests these improvements are still on shaky ground. Models are achieving physically realistic entrainment rates by rapidly adjusting the cloud and inversion structure in model-specific ways to bring entrainment warming and drying into a rough balance with the combined effects of radiative cooling and surface fluxes. This points to the need for continuing careful study of the optimal representation of entrainment and numerical discretization in order to realistically predict LWP and stratocumulus cloud radiative properties in GCMs.

Acknowledgments. Zhu and Bretherton acknowledge support from NASA Grant NAGS5-10624. Stevens acknowledges support from NASA Grant ATM-0097053. This work was performed while Golaz held a National Research Council Research Associateship Award at the Naval Research Laboratory, Monterey, California.

\section{REFERENCES}

Bechtold, P., S. K. Krueger, W. S. Lewellen, E. van Meijgaard, C. H. Moeng, D. A. Randall, A. van Ulden, and S. Wang, 1996: Modeling a stratocumulus-topped PBL: Intercomparison among different one-dimensional codes and with large eddy simulation. Bull. Amer. Meteor. Soc., 77, 2033-2042.

Bretherton, C. S., and M. C. Wyant, 1997: Moisture transport, lower tropospheric stability, and decoupling of cloud-topped boundary layers. J. Atmos. Sci., 54, 148-167.

_ , and Coauthors, 1999: An intercomparison radiatively-driven entrainment and turbulence in a smoke cloud, as simulated by different numerical models. Quart. J. Roy. Meteor. Soc., 125, 391-423.

Browning, K. A., 1993: The GEWEX Cloud System Study (GCSS). Bull. Amer. Meteor., 74, 387-399.

Cheng, A., K.-M. Xu, and J.-C. Golaz, 2004: The liquid water oscillation in modeling boundary layer cumuli with thirdorder turbulence closure models. J. Atmos. Sci., 61, 16211629.

Deardorff, J. W., 1980: Cloud top entrainment instability. J. Atmos. Sci., 37, 131-147.

Duynkerke, P. J., and Coauthors, 2004: Observations and numerical simulations of the diurnal cycle of the EUROCS stratocumulus case. Quart. J. Roy. Meteor. Soc., 130, 3269-3296. 
Golaz, J.-C., V. E. Larson, and W. R. Cotton, 2002: A PDF-based model for boundary layer clouds. Part I: Method and model description. J. Atmos. Sci., 59, 3540-3551.

Gordon, C. T., A. Rosati, and R. Gudgel, 2000: Tropical sensitivity of a coupled model to specified ISCCP low clouds. $J$. Climate, 13, 2239-2260.

Grenier, H., and C. S. Bretherton, 2001: A moist PBL parameterization for large-scale models and its application to subtropical cloud-topped marine boundary layers. Mon. Wea. Rev., 129, 357-377.

Hack, J. J., 1994: Parameterization of moist convection in the National Center for Atmospheric Research community climate model (CCM2). J. Geophys. Res., 99, 5551-5568.

Holtslag, A. A. M., and B. A. Boville, 1993: Local versus nonlocal boundary-layer diffusion in a global climate model. J. Climate, 6, 1825-1842.

Larson, V. E., and J.-C. Golaz, 2005: Using probability density functions to derive consistent closure relationships among higher-order moments. Mon. Wea. Rev., 133, 1023-1042.

Lenderink, G., and A. A. M. Holtslag, 2000: Evaluation of the kinetic energy approach for modeling turbulent fluxes in stratocumulus. Mon. Wea. Rev., 128, 244-258.

— , and — 2004: An updated length scale formulation for turbulent mixing in clear and cloudy boundary layers. Quart. J. Roy. Meteor. Soc., 130, 3405-3427.

Lock, A. P., 2001: The numerical representation of entrainment in parameterizations of boundary layer turbulent mixing. Mon. Wea. Rev., 129, 1148-1163.

, A. R. Brown, M. R. Bush, G. M. Martin, and R. N. B. Smith, 2000: A new boundary layer mixing scheme. Part I: Scheme description and single-column model tests. Mon. Wea. Rev., 128, 3187-3199.

Martin, G. M., M. R. Bush, A. R. Brown, A. P. Lock, and R. N. B. Smith, 2000: A new boundary layer mixing scheme. Part II: Tests in climate and mesoscale models. Mon. Wea. Rev., 128, 3200-3217.

Moeng, C.-H., and Coauthors, 1996: Simulation of a stratocumulus-topped planetary boundary layer: Intercomparison among different numerical codes. Bull. Amer. Meteor. Soc., 77, 261-278.

Randall, D. A., 1980: Conditional instability of the first kind upside-down. J. Atmos. Sci., 37, 125-130.

Stevens, B., and Coauthors, 2003a: Dynamics and chemistry of marine stratocumulus-DYCOMS-II. Bull. Amer. Meteor. Soc., 84, 579-593.

- , and Coauthors, 2003b: On entrainment rates in nocturnal marine stratocumulus. Quart. J. Roy. Meteor. Soc., 129, 3469 3493.

— and Coauthors, 2005: Evaluation of large-eddy simulations via observations of nocturnal marine stratocumulus. Mon. Wea. Rev., 133, 1443-1462.

Tompkins, A. M., 2002: A prognostic parameterization for the subgrid-scale variability of water vapor and clouds in largescale models and its use to diagnose cloud cover. J. Atmos. Sci., 59, 1917-1942.

— , and Coauthors, 2004: Moist physical processes in the IFS: Progress and plan. ECMWF Tech. Memo., 93 pp.

Wang, S., B. A. Albrecht, and P. Minnis, 1993: A regional simulation of marine boundary-layer clouds. J. Atmos. Sci., 50, 4022-4040. 